\title{
A Moderate to High Red to Far-red Light Ratio from Light-emitting Diodes Controls Flowering of Short-day Plants
}

\author{
Daedre S. Craig ${ }^{1}$ and Erik S. Runkle ${ }^{2}$ \\ Department of Horticulture, 1066 Bogue Street, Michigan State University, East Lansing, MI 48824
}

\begin{abstract}
Additional INDEX words. LEDs, long days, phytochrome, protected cultivation
Abstract. In protected cultivation of short-day (SD) plants, flowering can be inhibited by lighting from incandescent (INC) lamps during the night. INC lamps are being phased out of production and replaced by light-emitting diodes (LEDs), but an effective spectrum to control flowering has not been thoroughly examined. We quantified how the red [R $(600$ to $700 \mathrm{~nm})]$ to far red [FR $(700$ to $800 \mathrm{~nm})]$ ratio (R:FR) of photoperiodic lighting from LEDs influenced flowering and extension growth of SD plants. Chrysanthemum (Chrysanthemum Xmorifolium), dahlia (Dahlia hortensis), and african marigold (Tagetes erecta) were grown at $20^{\circ} \mathrm{C}$ under a 9-hour day with or without a 4-hour night interruption (NI) treatment by INC lamps or LEDs with seven different R:FR ranging from all $R$ to all $F R$. Flowering in the most sensitive species, chrysanthemum, was not inhibited by an R:FR of 0.28 or lower, whereas an R:FR of 0.66 or above reduced flowering percentage. Flowering in dahlia was incomplete under the FR-only NI and under SDs, but time to flower was similar under the remaining NI treatments. The least sensitive species, african marigold, flowered under all treatments, but flowering was most rapid under the FR-only NI and under SDs. For all species, stem length increased quadratically as the R:FR of the NI increased, reaching a maximum at $R: F R$ of $\approx 0.66$. We conclude that in these SD plants, a moderate to high R:FR (0.66 or greater) is most effective at interrupting the long night, blue light is not needed to interrupt the night, and FR light alone does not regulate flowering.
\end{abstract}

Many plants exhibit a photoperiodic flowering response, including a broad range of field and ornamental crops (Erwin and Warner, 2002; Mattson and Erwin, 2005; Runkle and Heins, 2003). This photoperiodic response is determined primarily by the duration of the dark period, also known as the critical night length (Thomas and Vince-Prue, 1997). Plants have been classified into photoperiodic response groups depending on how the critical night length influences flowering. Short-day plants (SDPs) flower most rapidly when uninterrupted dark periods are longer than some genotype-specific critical night length (Vince, 1969). Within the SDP response category, plants can be further classified based on whether SDs are required for flowering (a qualitative response) or hasten it (a quantitative response). Photoperiodic (low-intensity) lighting is used by commercial crop producers to alter the natural photoperiod (e.g., to extend the natural daylength or to interrupt the dark period) to manipulate flowering.

The spectral quality of photoperiodic lighting can influence flowering responses. Light quality is perceived by three identified families of plant photoreceptors: cryptochromes, ultraviolet receptors, and phytochromes (Kami et al., 2010). Cryptochromes have been identified in many plant species and mediate a variety of light responses, including playing a role in flowering time regulation in arabidopsis [Arabidopsis thaliana (Cashmore et al., 1999; Mockler et al., 2003)]. The phytochrome photoreceptors

Received for publication 12 Dec. 2012. Accepted for publication 20 Mar. 2012. We gratefully acknowledge funding by the USDA National Institute of Food and Agriculture's Specialty Crop Research Initiative (Grant 2010-5118121369), Michigan's plant agriculture initiative at Michigan State University (Project GREEEN), and horticulture companies providing support for Michigan State University floriculture research. We also thank Mike Olrich for his greenhouse technical assistance and Catherine Whitman for her input in the preparation of the manuscript.

${ }^{1}$ Former Graduate Student

${ }^{2}$ Corresponding author. E-mail: runkleer@msu.edu. mediate extension growth and flowering in photoperiodic plants (Smith, 1994). Five types of phytochrome have been identified in arabidopsis and designated A to E (Kami et al., 2010). Studies with phytochrome mutants of arabidopsis have shown that phyA and phyB play dominant roles mediating flowering and stem extension, respectively, in response to light quality (Franklin and Quail, 2010). Phytochrome exists in a R (600 to $700 \mathrm{~nm}$; peak absorption at $660 \mathrm{~nm}$ ) and a FR (700 to $800 \mathrm{~nm}$; peak absorption at $730 \mathrm{~nm}$ ) absorbing form, $\mathrm{P}_{\mathrm{R}}$ and $\mathrm{P}_{\mathrm{FR}}$, respectively (Hayward, 1984; Sager et al., 1988). The R:FR incident on the plant influences the phytochrome photoequilibria $\left(\mathrm{P}_{\mathrm{FR}} / \mathrm{P}_{\mathrm{R}+\mathrm{FR}}\right)$ within the plant. On absorbing R light, $P_{R}$ converts mainly to the $\mathrm{P}_{\mathrm{FR}}$ form. The $\mathrm{P}_{\mathrm{FR}}$ form largely converts back to the $\mathrm{P}_{\mathrm{R}}$ form on absorbing FR light or during a natural, gradual conversion during the dark period (Thomas and Vince-Prue, 1997). Although the total pool of phytochrome in the plant is relatively constant, because natural light environments are ever-changing, the relative amounts of $\mathrm{P}_{\mathrm{FR}}$ and $\mathrm{P}_{\mathrm{R}}$, and thus the overall $\mathrm{P}_{\mathrm{FR}} / \mathrm{P}_{\mathrm{R}+\mathrm{FR}}$, also fluctuate throughout the day.

In photoperiodic crops, the $\mathrm{P}_{\mathrm{FR}} / \mathrm{P}_{\mathrm{R}+\mathrm{FR}}$, through different types of phytochromes, influences flowering. $\mathrm{P}_{\mathrm{FR}}$ is the active form of phytochrome, which translocates to the nucleus on receiving light signals and activates downstream pathways (Franklin and Quail, 2010). Under a long, uninterrupted night, the $\mathrm{P}_{\mathrm{FR}}$ form of phytochrome slowly converts to the $\mathrm{P}_{\mathrm{R}}$ form, leaving insufficient $\mathrm{P}_{\mathrm{FR}}$ to inhibit flowering. However, if $\mathrm{R}$ light is provided during the long night, $\mathrm{P}_{\mathrm{R}}$ is converted to $\mathrm{P}_{\mathrm{FR}}$ (creating a greater $\mathrm{P}_{\mathrm{FR}} / \mathrm{P}_{\mathrm{R}+\mathrm{FR}}$ ), which inhibits flowering in SDPs. The $\mathrm{P}_{\mathrm{FR}} / \mathrm{P}_{\mathrm{R}+\mathrm{FR}}$ also influences extension growth, especially in shade-avoiding plants.

Incandescent lamps are commonly used as photoperiodic lighting to control development of crops, because they emit an effective spectrum and are inexpensive. However, INC lamps are very energy-inefficient and are being phased out of production in many parts of the world (Waide, 2010). LEDs are an attractive 
technology for NI lighting of photoperiodic crops. Compared with conventional lamps, LEDs have many desirable characteristics including a very long operating life, narrow bandwidth capability, full instantaneous irradiance when powered, and continually improving electrical efficiencies (Bourget, 2008; Morrow, 2008). Furthermore, LEDs allow researchers to analyze the effects of specific wavebands without extraneous light. Many of the original studies on photoperiodic light quality were limited by the lighting technology of the time. The use of photoselective filters and tinted lamps may have introduced confounding variables into these early experiments such as differences in photon flux between treatments and/or inclusion of potentially confounding, extraneous wavelengths (Borthwick et al., 1952; Cathey and Borthwick, 1957; Downs, 1956).

The objectives of the present study were to use LEDs to quantify the impact of the R:FR of NI lighting on flowering of $\mathrm{SD}$ ornamental crops and to compare plant responses with those under traditional INC lamps. To our knowledge, this is the first study that has identified how R:FR ratios control the flowering response of SDPs without the confounding effects of other light wavebands.

\section{Materials and Methods}

Plant material and culture. On 8 Feb. 2011, 7 - to 10-d-old seedlings of african marigold 'American Antigua Yellow' grown in 288-cell $(6 \mathrm{~mL})$ plug trays and rooted cuttings of chrysanthemum 'Adiva Purple' and dahlia 'Dahlinova Figaro Mix' grown in 36-cell (32 mL) liner trays were received from a commercial greenhouse (C. Raker \& Sons, Litchfield, MI). The young plants were subsequently grown under non-inductive long days [natural daylength extended from 0600 to $2200 \mathrm{HR}$ by high-pressure sodium (HPS) lamps] in a research greenhouse at $20^{\circ} \mathrm{C}$ until transfer to the NI treatments.

African marigold and dahlia were transferred to NI treatments on 14 Feb. and chrysanthemum on 25 Feb. On transfer, 10 plants per treatment of each species were transplanted into $10-\mathrm{cm}(430 \mathrm{~mL})$ round plastic pots containing a commercial peatperlite medium (Suremix; Michigan Grower Products, Galesburg, MI). All species were thinned to one plant per pot on the day of transplant. The experiment was repeated in the spring with the same treatments and greenhouse environment as previously described. Dahlia 'Dahlinova Figaro Mix' was replaced by dahlia 'Carolina Burgundy', which were propagated by stem cuttings harvested from plants received from C. Raker \& Sons on 21 Apr. Chrysanthemums from the first replicate of the experiment were grown as stock plants under long days (LDs), and cuttings were subsequently harvested and rooted for the second replicate. Chrysanthemum and dahlia shoot-tip cuttings (two or three nodes) were rooted in 51-cell liner trays filled with 50\% Sure-mix and 50\% screened coarse perlite (Therm-O-Rock East, New Eagle, PA). Cuttings were rooted under LD in a propagation greenhouse as described by Lopez and Runkle (2008). For the second replicate, african marigold was received and placed in NI treatments on 26 May and chrysanthemum and dahlia were transferred on 7 July.

LED LAMPS AND NI TREATMENTS. Opaque black cloth enclosed all greenhouse benches from 1700 to $0800 \mathrm{HR}$, creating a 9-h SD. One bench was designated the SD control bench. Above the remaining benches, NI lighting was delivered from 2230 to 0230 HR by either 40-W INC lamps or customized LED fixtures containing three $\mathrm{R}$ and/or FR LED diodes per lamp developed by CCS Inc. (Kyoto, Japan). Lamps were paired to produce a total of six diodes and thus, seven R:FR ratios were created (Fig. 1). The R and FR LEDs had peak wavelengths of $660 \mathrm{~nm}$ and $735 \mathrm{~nm}$, respectively, which correspond with peaks of phytochrome absorption (Sager et al., 1988). Because the photon flux from the R LEDs was approximately twice that from the FR LEDs, all R diodes were filtered with two layers of aluminum mesh.

Light spectra under each treatment were measured by two portable spectroradiometers [LI-1800 (LI-COR, Lincoln, NE) and PS-200 (StellarNet, Tampa, FL)]. Spectral measurements were taken at regular intervals across the bench area of each treatment. Mean photon flux from 600 to $800 \mathrm{~nm}$ was 1.3 to $1.6 \mu \mathrm{mol} \cdot \mathrm{m}^{-2} \cdot \mathrm{s}^{-1}$ for all NI treatments, and plants were positioned on benches only where the photon flux was $0.7 \mu \mathrm{mol} \cdot \mathrm{m}^{-2} \cdot \mathrm{s}^{-1}$ or greater. The R:FR was measured and described using 100- or 10-nm-wide wavebands and the phytochrome photoequilibria $\left(\mathrm{P}_{\mathrm{FR}} / \mathrm{P}_{\mathrm{R}}+\mathrm{FR}\right)$ was calculated for each treatment following Sager et al. (1988) (Fig. 1).

Greenhouse ENVIROnMent. The experiment was conducted in a glass-glazed, environmentally controlled greenhouse at a constant temperature set point of $20^{\circ} \mathrm{C}$. In late April, whitewash was applied externally to the greenhouse glazing to reduce light transmission by $30 \%$ to $40 \%$ and, thus, decrease radiant heating. All treatments received supplemental lighting from 0800 to 1600 HR provided by HPS lamps delivering a photosynthetic photon flux $(P P F)$ of 60 to $90 \mu \mathrm{mol} \cdot \mathrm{m}^{-2} \cdot \mathrm{s}^{-1}$ at plant height. The HPS lamps were operated by an environmental control computer

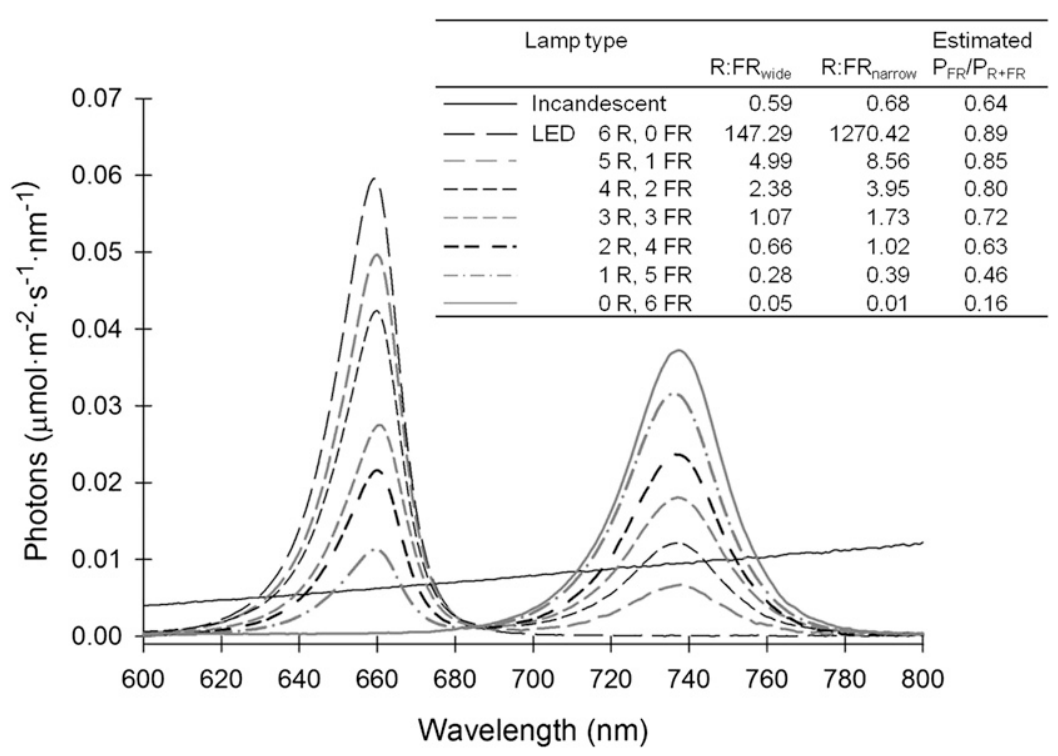

Fig. 1. Light quality emitted from incandescent and light-emitting diodes (LEDs) between 600 and 800 $\mathrm{nm}$. The number of red (R) and far-red (FR) diodes per lamp pair is indicated for each LED treatment. $\mathrm{R}$ to far-red FR ratios and estimated phytochrome photoequilibria $\left(\mathrm{P}_{\mathrm{FR}} / \mathrm{P}_{\mathrm{R}+\mathrm{FR}}\right)$ values (Sager et al., 1988) for the night interruption treatments are given in the inset table. $R: F_{\text {wide }}$ equals 600 to 700 : 700 to $800 \mathrm{~nm}$; R:FR narrow equals 655 to $665: 725$ to $735 \mathrm{~nm}$. 
and were switched on when the ambient $P P F$ outside the greenhouse was less than $185 \mu \mathrm{mol} \cdot \mathrm{m}^{-2} \cdot \mathrm{s}^{-1}$, and switched off when ambient $P P F$ was greater than $370 \mu \mathrm{mol} \cdot \mathrm{m}^{-2} \cdot \mathrm{s}^{-1}$. Line quantum sensors (Apogee Instruments, Logan, UT) were positioned at plant height throughout the greenhouse. The sensors measured $P P F$ every $10 \mathrm{~s}$, and hourly averages were recorded by a data logger (CR10; Campbell Scientific, Logan, UT). The mean photosynthetic daily light integrals were 15.2 and $14.5 \mathrm{~mol} \cdot \mathrm{m}^{-2} \cdot \mathrm{d}^{-1}$ for the first and second experiment replications, respectively.

Air temperature was measured on each greenhouse bench by an aspirated thermocouple [36-gauge $(0.127-\mathrm{mm}$ diameter) type E] every $10 \mathrm{~s}$, and hourly averages were recorded by a data logger. The actual mean daily temperature was 19.9 and $21.9^{\circ} \mathrm{C}$ for the first and second experiments, respectively. When the nighttime air temperature at bench level was less than $18.9^{\circ} \mathrm{C}$, a $1500-\mathrm{W}$ electric heater, controlled by a data logger, provided supplemental heat during the night. Plants were irrigated as necessary with reverse-osmosis water supplemented with a water-soluble fertilizer providing (milligrams per liter) 125 nitrogen, 12 phosphorus, 100 potassium, 65 calcium, 12 magnesium, 1.0 iron and copper, 0.5 manganese and zinc, 0.3 boron, and 0.1 molybdenum (MSU RO Water Special; GreenCare Fertilizers, Chicago, IL).

Data collection and analysis. Plant height (from media surface to shoot tip) was measured on the day of transplant, and nodes were counted on each plant. The date of first flowering was recorded; plants were considered flowering when at least $50 \%$ of the ray flowers of an inflorescence were reflexed. At flowering, the total number of inflorescences and plant height and number of nodes below the first flower (replicate 2 only) were recorded. Plants that did not have an open flower within 150\% of average flowering time were considered non-flowering. Time from transplant to first flower as well as node number increase were calculated for each plant. Data were analyzed with SAS (Version 9.1; SAS Institute, Cary, NC) and data were pooled between replications if statistical interactions between main effects and replication were not significant ( $P \geq 0.05$ ). Regression analysis was performed with SAS to relate the data parameters to the estimated $\mathrm{P}_{\mathrm{FR}} / \mathrm{P}_{\mathrm{R}+\mathrm{FR}}$ of the plants in the NI treatments.

\section{Results}

All chrysanthemum plants flowered under the FR-only NI treatment and under SDs in both replicates (Fig. 2A). Among the other treatments, flowering percentage generally decreased with increasing R:FR. For plants that did flower under an LED NI with a R:FR wide 0.66 or greater $\left(\mathrm{P}_{\mathrm{FR}} / \mathrm{P}_{\mathrm{R}+\mathrm{FR}} 0.63\right.$ or greater $)$, flowering was delayed by $42 \mathrm{~d}$ compared with plants under SDs or FR-only NIs (Fig. 2B). Similarly, under the INC NI, flowering was delayed by $30 \mathrm{~d}$ compared with under SDs or FR-only NIs. Inflorescence number was greatest ( 163 or greater) under a moderate $R: F_{\text {wide }}$ and $\approx 43$ under the FR-only NIs or SDs [Fig. 2C (note that inflorescence number was divided by 10 in the figure)]. Extension growth of plants was greater in the second experimental replicate but trends were similar (Fig. 2D; Table 1). Height increased quadratically as the R:FR increased to a maximum at $\mathrm{R}: \mathrm{FR}_{\mathrm{wide}} \approx 0.66\left(\mathrm{P}_{\mathrm{FR}} /\right.$ $\mathrm{P}_{\mathrm{R}+\mathrm{FR}} 0.63$ or greater). Plants grown under the FR-only NIs were 4.3 and $7.8 \mathrm{~cm}$ shorter than plants under INC NIs in replicates 1 and 2, respectively. Under SDs, extension growth was $8.2 \mathrm{~cm}$ less in replicate 1 and $14.9 \mathrm{~cm}$ less in replicate 2 compared with plants under the INC NIs.

Flowering of dahlia 'Figaro Mix' was incomplete under the FR-only NI and SD treatments (40\% and 50\%, respectively), which was surprising because dahlia is considered an SD plant

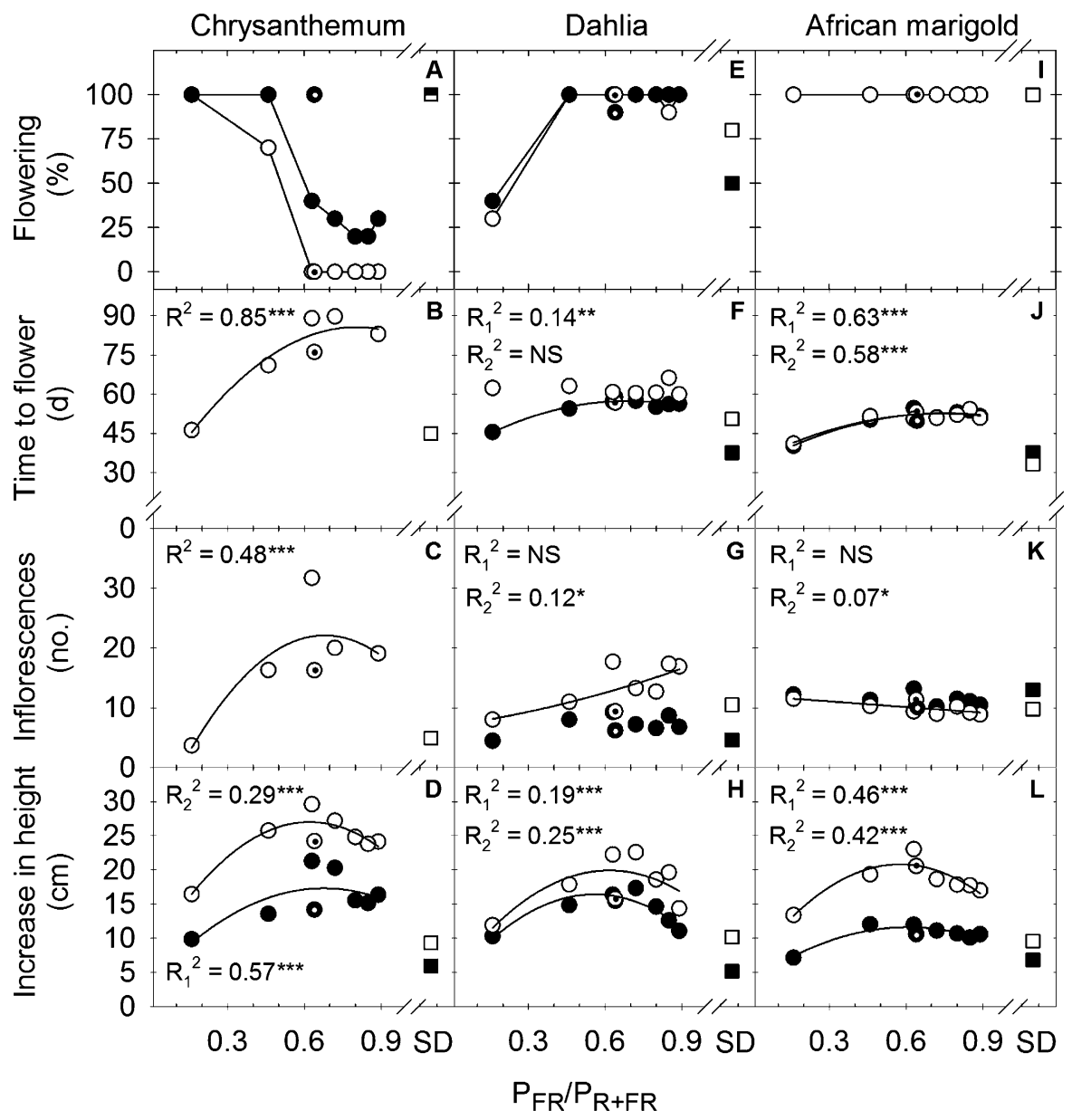

Fig. 2. (A-L) Influence of the estimated $\mathrm{P}_{\mathrm{FR}} / \mathrm{P}_{\mathrm{R}+\mathrm{FR}}$ of night interruption lighting on flowering characteristics and extension growth of the short-day (SD) plants chrysanthemum 'Adiva Purple', dahlia 'Figaro Mix' (solid symbols; replicate 1), dahlia 'Carolina Burgundy' (open symbols; replicate 2), and african marigold 'American Antigua Yellow'. Single open data symbols indicate pooled data. With the exception of flowering percentage, associated correlation coefficients $\left(R^{2}\right)$ are presented. Multiple plots indicate replicate 1 data (solid symbols) and replicate 2 data (open symbols) with associated $R_{1}{ }^{2}$ and $R_{2}{ }^{2}$ values, respectively. Dotted circle symbols indicate the incandescent control treatment. Square data symbols indicate the SD control treatment. Data for chrysanthemum inflorescence number has been divided by 10 . NS, *,**,*** indicate nonsignificant or significant at $P \leq 0.05,0.01$, and 0.001 , respectively. See Table 1 for regression equations. $\mathrm{P}_{\mathrm{FR}} / \mathrm{P}_{\mathrm{R}+\mathrm{FR}}=$ estimated phytochrome photoequilibria values (Sager et al., 1988). 
Table 1. Parameters of regression analysis relating days to flower, inflorescence number, and increase in height to the estimated phytochrome photoequilibrium of plants in the night interruption lighting treatments.

\begin{tabular}{llclc}
\hline Species & \multicolumn{1}{c}{ Parameter } & Replicate & \multicolumn{1}{c}{ Regression equation } & $R^{2}$ \\
\hline Chrysanthemum & Days to flower & Pooled & $\mathrm{y}=25.3+144.8 \mathrm{x}-94.5 \mathrm{x}^{2}$ & $0.85^{* * *}$ \\
'Adiva Purple' & Inflorescence no. & Pooled & $\mathrm{y}=-78.8+817.8 \mathrm{x}-608.4 \mathrm{x}^{2}$ & $0.48^{* * *}$ \\
& Height increase & 1 & $\mathrm{y}=7.9+61.5 \mathrm{x}-49.5 \mathrm{x}^{2}$ & $0.57^{* * *}$ \\
& Height increase & 2 & $\mathrm{y}=3.6+40.5 \mathrm{x}-29.9 \mathrm{x}^{2}$ & $0.29^{* * *}$ \\
Dahlia 'Figaro Mix' & Days to flower & 1 & $\mathrm{y}=36.8+59.8-43.5 \mathrm{x}^{2}$ & $0.14^{* * *}$ \\
& Height increase & 1 & $\mathrm{y}=2.9+48.0 \mathrm{x}-42.5 \mathrm{x}^{2}$ & $0.19^{* * *}$ \\
Dahlia 'Carolina & Inflorescence no. & 2 & $\mathrm{y}=7.5+5.0 \mathrm{x}+5.6 \mathrm{x}^{2}$ & $0.12^{*}$ \\
Burgundy' & Height increase & 2 & $\mathrm{y}=4.6+50.1 \mathrm{x}-40.7 \mathrm{x}^{2}$ & $0.25^{* * *}$ \\
African marigold & Days to flower & 1 & $\mathrm{y}=32.8+53.0 \mathrm{x}-35.2 \mathrm{x}^{2}$ & $0.63^{* * *}$ \\
'American & Days to flower & 2 & $\mathrm{y}=35.0+47.3 \mathrm{x}-31.9 \mathrm{x}^{2}$ & $0.58^{* * *}$ \\
Antigua Yellow' & Inflorescence no. & 2 & $\mathrm{y}=12.0-3.1 \mathrm{x}$ & $0.07 *$ \\
& Height increase & 1 & $\mathrm{y}=3.7+26.5 \mathrm{x}-21.8 \mathrm{x}^{2}$ & $0.46^{* * *}$ \\
& Height increase & 2 & $\mathrm{y}=6.4+50.2 \mathrm{x}-43.6 \mathrm{x}^{2}$ & $0.42^{* * *}$ \\
\hline
\end{tabular}

$*, * * *$ indicate significant at $P \leq 0.05$ and 0.001 , respectively.

(Fig. 2E). However, the 'Figaro Mix' plants that flowered under the FR-only NI and SD treatments did so slightly earlier than those under the other LD treatments: flowering was hastened by 11 and $19 \mathrm{~d}$ under FR-only NI and SD, respectively, compared with plants in R:FR $\mathrm{wide}_{\text {treatments }} 0.28$ or greater $\left(\mathrm{P}_{\mathrm{FR}} / \mathrm{P}_{\mathrm{R}+\mathrm{FR}} 0.46\right.$ or greater) (Fig. $\left.2 \mathrm{~F}\right)$. Inflorescence number was variable and statistically similar under all treatments (Fig. 2G). Extension growth exhibited a quadratic trend and was greatest under moderate $\mathrm{R}: \mathrm{FR}_{\mathrm{wide}}$ treatments (Fig. 2H). Height increase of plants grown under FR NIs and SDs was 5.2 and $10.4 \mathrm{~cm}$ less, respectively, than that of plants grown under the INC NIs.

Flowering of dahlia 'Carolina Burgundy' was incomplete under FR-only NI and SD treatments, whereas nearly all plants flowered under the other treatments (Fig. 2E). Time to flower was similar under all NI treatments but $11 \mathrm{~d}$ earlier under SDs (Fig. 2F). Node number at flowering was variable and averaged from 13 to 18 in all treatments (data not shown). There was a small, positive correlation between inflorescence number and

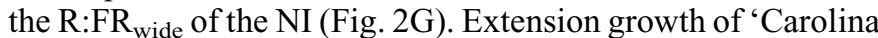
Burgundy' exhibited a quadratic trend and was greatest under

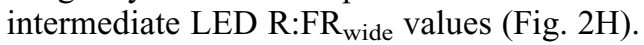

All african marigold plants flowered under all treatments (Fig. 2I), but plants in both replications flowered 10 to $20 \mathrm{~d}$ earlier under SDs or the FR-only NI treatment compared with the other treatments (Fig. 2J). Time to flower under the remaining LED treatments (R:FR $\mathrm{Fide}_{\text {wide }} 0.28$ or greater) and under INC lamps was similar. However, plants under SDs or the FRonly NI treatment developed five or six nodes from transplant to flowering, whereas those under the other NI treatments developed 11 to 13 nodes (data not shown). There was a small negative correlation between inflorescence number and the $\mathrm{R}: \mathrm{FR}_{\text {wide }}$ of the NI in the second experimental replicate (Fig. 2K). Extension growth of plants grown under the FR-only NI treatment or under SDs was 3.9 to $5.8 \mathrm{~cm}$ less than that of plants under the other NI treatments (Fig. 2L).

\section{Discussion}

In several classic photoperiod studies, flowering of cocklebur [Xanthium strumarium (Borthwick et al., 1952; Downs, 1956)], chrysanthemum (Cathey and Borthwick, 1957), and soybean [Glycine max (Downs, 1956)] could be inhibited by an $R$ night break, which promotes formation of $\mathrm{P}_{\mathrm{FR}}$ and thus increases the $\mathrm{P}_{\mathrm{FR}} / \mathrm{P}_{\mathrm{R}+\mathrm{FR}}$. A subsequent FR exposure, however, could reverse the flowering inhibition imposed by $\mathrm{R}$ light, showing that the inhibition of flowering in SDPs depends on $\mathrm{R}$ light and the resulting formation of the $\mathrm{P}_{\mathrm{FR}}$ form of phytochrome (Thomas and Vince-Prue, 1997). Although it is well established that $\mathrm{R}$ light is most effective at inhibiting flowering in SDPs, some plants are more sensitive than others (Cathey and Borthwick, 1957; Downs, 1956). In addition, these classic R:FR studies used broad-spectrum lamps with or without photoselective filters, which could have introduced confounding wavelengths such as blue light into these experiments.

Like in previous studies (Borthwick et al., 1952; Cathey and Borthwick, 1957; Downs, 1956), R light was as effective as INC for flower inhibition among the SDP species we studied. LED treatments with an R:FR wide $_{\text {of }} 0.66$ or greater and the INC lamps $\left(\mathrm{R}: \mathrm{FR}_{\text {wide }}=0.59\right)$ inhibited flowering the most. Therefore, LEDs with a moderate-to-high R:FR are a viable replacement for INC lamps to inhibit flowering of SDPs. In addition, because the LED treatments did not emit blue light, and flowering was similar to that under INC lamps (which emit a small amount of blue), blue light is apparently not needed to regulate flowering of these SDPs tested. A variety of crop characteristics (e.g., internode length, branching, and bud number) can be influenced using LEDs with different R:FR. However, in terms of flower inhibition and height control, the NI treatments that primarily emitted $\mathrm{R}$ light were most effective for the SDP species studied.

Short-day plants differ in their sensitivity to the R:FR and duration of NI lighting. Only $1 \mathrm{~min}$ of $\approx 11 \mu \mathrm{mol} \cdot \mathrm{m}^{-2} \cdot \mathrm{s}^{-1}$ light from an INC lamp during a long night was needed to inhibit flowering of cocklebur and soybean (Downs, 1956), whereas several hours of light at the same irradiance, for multiple cycles, was needed to inhibit flowering of chrysanthemum (Cathey and Borthwick, 1957). Chrysanthemum appears to be particularly sensitive to the light quality of the NI. Flowering can be inhibited by several hours of NI from a fluorescent (FL) or INC lamp or by $1 \mathrm{~min}$ of low-intensity FL light (Cathey and Borthwick, 1957). However, 1 min of high-intensity INC light was not sufficient to inhibit flowering. The R:FR of INC light is much lower than that of FL light. Therefore, a brief INC NI converts less phytochrome to the $\mathrm{P}_{\mathrm{FR}}$ form than would a brief FL NI. Theoretically, R light is most effective at inhibiting flowering of SDPs because the high R:FR of FL light is sufficient to convert enough phytochrome into the $\mathrm{P}_{\mathrm{FR}}$ form to inhibit flowering, even at low intensity and short duration.

In our study, we also observed variations in sensitivity to the light quality of the NI. In agreement with Cathey and Borthwick (1957), chrysanthemum was highly sensitive to the R:FR of the NI, at least compared with the other species tested. Flowering of chrysanthemum was inhibited more by NI treatments with higher R:FR compared with those with lower R:FR. Because 
chrysanthemum is an obligate SDP, one might expect a more dramatic response to the R:FR than in dahlia or african marigold (two facultative SDPs). Surprisingly, flowering percentage of chrysanthemum grown under the INC NI treatment was 100 in experimental replicate 1 and 0 in replicate 2. Plants in the first replicate were received from a commercial grower and some may have been exposed to inductive photoperiods before arrival; alternately, we may have had a burned out INC bulb that went unnoticed for a time sufficient to induce them. Within our populations of dahlia plants, sensitivity to NI light quality was variable. Flowering percentage was lowest under the FR-only NI and SD treatments. Among the remaining treatments, the effect on flowering time was similar regardless of the R:FR of the NI. Although these results were unexpected, a variety of photoperiodic responses have been observed in dahlia and our SD conditions may not have been optimal for the cultivars we used. When 'Royal Dahlietta Yellow' were grown under photoperiods ranging from 10 to $24 \mathrm{~h}$, the optimal photoperiod for flowering was 12 to $14 \mathrm{~h}$ (Brøndum and Heins, 1993). Flowering percentage was reduced and flowers developed abnormally in two cultivars of dahlia grown under 8-h photoperiods compared with plants grown under a 4-h NI or 16-h photoperiod (Durso and De Hertogh, 1977). Some varieties require $\mathrm{SD}$ for flower induction but $\mathrm{LD}$ for optimal flower bud development (Legnani and Miller, 2001). African marigold exhibited a weakly facultative SD flowering response and was the least photoperiodic species in our study because all plants flowered in all treatments, and flowering was delayed similarly under all NI treatments with an R:FR wide 0.28 or greater.

Interestingly, flowering percentage and time to flower for each species were similar under SDs and the FR NI, indicating that the FR-only NI was largely ineffective and perceived as an $\mathrm{SD}$. Because $\mathrm{R}$ light is most effective at inhibiting flowering of SDPs, we postulated that as the proportion of $\mathrm{R}$ light relative to FR light increased (as the R:FR increased), inhibition of flowering in SDPs would progressively increase. Indeed, the higher R:FR NI treatments were more effective and those without $\mathrm{R}$ light were relatively ineffective. Therefore, it appears that some threshold amount of R light (or some threshold R:FR value) is required for SDPs to perceive an NI. The threshold $\mathrm{R}: \mathrm{FR}_{\text {wide }}$ for delaying flowering was 0.66 or greater $\left(\mathrm{P}_{\mathrm{FR}} / \mathrm{P}_{\mathrm{R}+\mathrm{FR}}\right.$ 0.63 or greater) for chrysanthemum and african marigold, but one was not identified for dahlia.

Regardless of photoperiodic classification, most plants exhibit some degree of shade-avoidance response. Natural daylight has an R:FR of $\approx 1.15$, and when plants detect a reduced R:FR (resulting from mutual shading, canopy cover, photoselective filters, etc.), extension growth increases in an effort to better harvest photosynthetic light (Smith, 1982). Alternatively, stem extension can be inhibited by growing plants under an increased R:FR, especially in shade-avoiding plants. For example, chrysanthemum grown under an FR-absorbing photoselective filter $(\mathrm{R}: \mathrm{FR}=2.2)$ were $20 \%$ shorter than plants grown under a neutral filter (Li et al., 2000). Yamada et al. (2008) used FR FL lamps $(\mathrm{R}: F R=0.01)$, INC lamps $(\mathrm{R}: \mathrm{FR}=0.65)$, and FL lamps (R:FR = 5.00) as NI treatments on lisianthus (Eustoma grandiflorum) 'Niel Peach Neo', an LD plant. Lamps with an R:FR of 0.01 and 0.65 increased internode length by $26 \%$ and $23 \%$, respectively, compared with plants grown without an NI. In contrast, plants grown with FL NI had 14\% shorter internodes than plants grown without an NI. Internode length of the LDPs petunia (Petunia $\times$ hybrida) 'Wave Purple Classic' and black-eyed susan (Rudbeckia hirta) 'Becky Cinnamon Bicolor' was significantly shorter when a 4-h NI was provided by compact FL lamps $(\mathrm{R}: \mathrm{FR}=8.5)$ than by $\mathrm{INC}$ lamps $(\mathrm{R}: \mathrm{FR}=$ 0.6) (Runkle et al., 2012).

In our study, plant height of chrysanthemum and dahlia 'Figaro' under an NI with a high proportion of R light (R:FR $\mathrm{Fide}_{\text {wide }}$ 2.38 or greater) was shorter than when grown under a moderate $\mathrm{R}: \mathrm{FR}_{\text {wide }}$ (0.66 and 1.07). Surprisingly, plants grown under the FR-only NI were generally shorter than plants in the other NI treatments. We anticipated that plants grown under the FR-only $\mathrm{NI}\left(\mathrm{R}: \mathrm{FR}_{\text {wide }}=0.05\right)$ would exhibit a shade-avoidance response and thus have greater stem elongation. However, because plants did not perceive an FR NI as an LD, flowering occurred earlier in development, so there was less time for stems to elongate before flowering. For example, marigold grown under an FR NI flowered with six fewer nodes than plants in the other NI treatments, so their overall height at first flowering was actually less.

Commercial growers have traditionally used INC lamps to provide photoperiod lighting because they are effective and inexpensive to install. However, INC lamps convert less than $10 \%$ of the energy consumed into visible light (Thimijan and Heins, 1983; Waide, 2010). With the phaseout of INC lamps, greenhouse growers will need other sources of light to control flowering of photoperiodic crops. As we have shown, LED technology provides an alternative to INC lamps for photoperiodic lighting. In addition to the improvements in lamp lifespan and energy efficiency, the narrow waveband nature of LEDs can be used to create lamps that are tailored to ornamental crop production needs. In SDPs, LEDs with a moderate to high R:FR are effective at preventing premature flowering and, thus, are a viable replacement for INC lamps.

\section{Literature Cited}

Borthwick, H.A., S.B. Hendricks, and M.W. Parker. 1952. The reaction controlling floral initiation. Proc. Natl. Acad. Sci. USA 38: 929-934.

Bourget, C.M. 2008. An introduction to light-emitting diodes. HortScience 43:1944-1946.

Brøndum, J.J. and R.D. Heins. 1993. Modeling temperature and photoperiod effects on growth and development of dahlia. J. Amer. Soc. Hort. Sci. 118:36-42.

Cashmore, A.R., J.A. Jarillo, Y.J. Wu, and D. Lu. 1999. Cryptochromes: Blue light receptors for plants and animals. Science 284 : 760-765.

Cathey, H.M. and H.A. Borthwick. 1957. Photoreversibility of floral initiation in chrysanthemum. Bot. Gaz. 119:71-76.

Downs, R.J. 1956. Photoreversbility of flower initiation. Plant Physiol. 31:279-284.

Durso, M. and A.A. De Hertogh. 1977. The influence of greenhouse environmental factors on forcing Dahlia variabilis Willd. J. Amer. Soc. Hort. Sci. 102:314-317.

Erwin, J.E. and R.M. Warner. 2002. Determination of photoperiodic response group and effect of supplemental irradiance on flowering of several bedding plant species. Acta Hort. 580:95-99.

Franklin, A.F. and P.H. Quail. 2010. Phytochrome functions in arabidopsis development. J. Expt. Bot. 61:11-24.

Hayward, P.M. 1984. Determination of phytochrome parameters from radiation measurements, p. 159-173. In: Smith, H. and M.G. Holmes (eds.). Techniques in photomorphogenesis. Academic Press, London, UK.

Kami, C., S. Lorrain, P. Homitschek, and C. Fankhauser. 2010. Chapter two-Light regulated plant growth and development. Plant Dev. 91:29-66. 
Legnani, G. and W.B. Miller. 2001. Manipulating dahlias. Greenhouse Product News 11:36-40.

Li, S.M., N.C. Rajapakse, R.E. Young, and R. Oi. 2000. Growth responses of chrysanthemum and bell pepper transplants to photoselective plastic films. Sci. Hort. 84:215-225.

Lopez, R.G. and E.S. Runkle. 2008. Photosynthetic daily light integral during propagation influences rooting and growth of cuttings and subsequent development of new guinea impatiens and petunia. HortScience 43:2052-2059.

Mattson, N.S. and J.E. Erwin. 2005. The impact of photoperiod and irradiance on flowering of several herbaceous ornamentals. Sci. Hort. 104:275-292.

Mockler, T., H. Yang, X. Yu, D. Parikh, Y. Cheng, S. Dolan, and C. Lin. 2003. Regulation of photoperiodic flowering by arabidopsis photoreceptors. Proc. Natl. Acad. Sci. USA 100:2140-2145.

Morrow, R.C. 2008. LED lighting in horticulture. HortScience 43: 1947-1950.

Runkle, E.S. and R.D. Heins. 2003. Photocontrol of flowering and extension growth in the long-day plant pansy. J. Amer. Soc. Hort. Sci. 128:479-485.

Runkle, E.S., S.R. Padhye, W. Oh, and K. Getter. 2012. Replacing incandescent lamps with compact fluorescent lamps may delay flowering. Sci. Hort. 143:56-61.
Sager, J.C., W.O. Smith, L.L. Edwards, and K.L. Cyr. 1988. Use of spectral data to determine photosynthetic efficiency and phytochrome photoequilibria. Trans. Amer. Soc. Agr. Eng. 31:1882-1889.

Smith, H. 1982. Light quality, photoperception and plant strategy. Annu. Rev. Plant Physiol. 33:481-518.

Smith, H. 1994. Sensing the light environment: The functions of the phytochrome family, p. 377-416. In: Kendrick, R.E. and G.H.M. Kronenberg (eds.). Photomorphogenesis in plants. 2nd Ed. Kluwer Academic Publishers, Dordrecht, The Netherlands.

Thimijan, R.W. and R.D. Heins. 1983. Photometric, radiometric, and quantum light units of measure: A review of procedures for interconversion. HortScience 18:818-822.

Thomas, B. and D. Vince-Prue. 1997. Photoperiodism in plants. 2nd Ed. Academic Press, San Diego, CA.

Vince, D. 1969. The regulation of flowering in long-day plants. Acta Hort. 14:91-95.

Waide, P. 2010. Phase out of incandescent lamps. 22 Jan. 2013. $<$ http://www.iea.org/publications/freepublications/publication/ phase_out-1.pdf>.

Yamada, A., T. Tanigawa, T. Suyama, and T. Matsuno. 2008. Night break treatment using different light sources promotes or delays growth and flowering of Eustoma grandiflorum (Raf.). Shinn. J. Jpn. Soc. Hort. Sci. 77:69-74. 